\title{
Publisher Correction: Marine microbial metagenomes sampled across space and time
}

\author{
Steven J. Biller ${ }^{1,+}{ }^{+}$, Paul M. Berube ${ }^{1}$, Keven Dooley ${ }^{1}$, Madeline Williams ${ }^{1}$, \\ Brandon M. Satinsky ${ }^{1}$, Thomas Hackl ${ }^{1}$, Shane L. Hogle ${ }^{1}$, Allison $\mathrm{Coe}^{1}$, Kristin Bergauer $^{2}$, \\ Heather A. Bouman ${ }^{3}$, Thomas J. Browning ${ }^{4}$, Daniele De Corte ${ }^{5}$, Christel Hassler 6 , \\ Debbie Hulston ${ }^{7}$, Jeremy E. Jacquot ${ }^{8}$, Elizabeth W. Maas ${ }^{9}$, Thomas Reinthaler ${ }^{2}$, Eva Sintes ${ }^{2}$, \\ Taichi Yokokawa ${ }^{5}$ \& Sallie W. Chisholm ${ }^{1,10}$
}

Correction to: Scientific Data https://doi.org/10.1038/sdata.2018.176 Published online 4 September 2018

Due to a typesetting error, 25 rows were omitted from Table 3 in the original version of this Data Descriptor. These missing rows correspond to the following sample names:

S0315, S0316, S0317, S0318, S0319, S0403, S0404, S0405, S0406, S0407, S0482, S0483, S0484, S0485, S0486, S0543, S0544, S0545, S0546, S0547, S0592, S0593, S0594, S0595, S0596.

In addition, a column in the table indicating the total bases for each sample was omitted.

Table 3 has been updated to include the missing data.

(i) Open Access This article is licensed under a Creative Commons Attribution 4.0 International License, which permits use, sharing, adaptation, distribution and reproduction in any medium or format, as long as you give appropriate credit to the original author(s) and the source, provide a link to the Creative Commons license, and indicate if changes were made. The images or other third party material in this article are included in the article's Creative Commons license, unless indicated otherwise in a credit line to the material. If material is not included in the article's Creative Commons license and your intended use is not permitted by statutory regulation or exceeds the permitted use, you will need to obtain permission directly from the copyright holder. To view a copy of this license, visit http://creativecommons.org/licenses/by/4.0/.

(C) The Author(s) 2019

\footnotetext{
${ }^{1}$ Department of Civil and Environmental Engineering, Massachusetts Institute of Technology, Cambridge, MA, 02139, USA. ${ }^{2}$ Department of Limnology and Bio-Oceanography, University of Vienna, Vienna, 1090, Austria. ${ }^{3}$ Department of Earth Sciences, University of Oxford, Oxford, OX1 3AN, UK. ${ }^{4}$ Marine Biogeochemistry Division, GEOMAR Helmholtz Centre for Ocean Research, Kiel, 24148, Germany. ${ }^{5}$ Research and Development Center for Marine Biosciences, Japan Agency for Marine-Earth Science and Technology, Yokosuka, 237-0061, Japan. ${ }^{6}$ Department F.-A. Forel for Environmental and Aquatic Sciences, University of Geneva, Geneva, 1211, Switzerland. ${ }^{7}$ National Institute of Water and Atmospheric Research, Auckland, 1010, New Zealand. ${ }^{8}$ Department of Biological Sciences, University of Southern California, Los Angeles, CA, 90089, USA. ${ }^{9}$ Ministry for Primary Industries, Napier, 4144, New Zealand. ${ }^{10}$ Department of Biology, Massachusetts Institute of Technology, Cambridge, MA, 02139, USA. 'Present address: Department of Biological Sciences, Wellesley College, Wellesley, MA, 02481, USA. Correspondence and requests for materials should be addressed to S.J.B. (email: sbiller@wellesley.edu) or S.W.C. (email: chisholm@ mit.edu)
} 